\title{
A parameter less stochastic optimization technique for tuning of speed PI controller of DTC induction motor drive
}

\author{
Naveen Goel $^{1}$, Saji Chacko ${ }^{2}$, R. N. Patel ${ }^{3}$ \\ ${ }^{1,3}$ Departement of Electrical and Electronics Engineering, SSTC, Bhilai (CG), India \\ ${ }^{2}$ Departement of Electrical Engineering, Govt. Polytechnic Durg, Durg (CG), India
}

\begin{tabular}{l} 
Article Info \\
\hline Article history: \\
Received Feb 11, 2019 \\
Revised Apr 15, 2019 \\
Accepted May 1, 2019 \\
\hline
\end{tabular}

Keywords:

Harmony search

Integral time absolute error

Jaya Algorithm

Voltage Source Inverter

\begin{abstract}
The Direct Torque Controlled (DTC) induction motor (IM) drives over the years have been the work force of industries. The popularity of this motor drive is due to the low cost and low maintenance of induction motor coupled with the fast dynamic response and simple control structure of direct torque control method. The robust performance of the DTC induction motor drive depends on the proper tuning of its speed controller. The proposed paper make use of the stochastic optimization technique namely the popular Harmony Search Algorithm and is compared with the parameter free Jaya Algorithm for tuning the gains of the speed proportional integral controller. Simulation studies in MATLAB/Simulink shows the success of the Jaya Optimization for improving the performance of DTC drive with respect to speed and torque peak over shoot and steady state error under different drive operating conditions.
\end{abstract}

Copyright (c) 2019 Institute of Advanced Engineering and Science. All rights reserved.

\section{Corresponding Author:}

Naveen Goel,

Departement of Electrical and Electronics Engineering,

Shri Shanracharya Technical Campus,

Bhilai (CG) 490020, India.

Email: ngoel18@gmail.com

\section{INTRODUCTION}

For critical application in industries an efficient controller for the DTC induction motor drive has to be designed. The IM being a highly cross coupled machine, the complexity of an efficient PI controller for high performance increases substantially. Conventionally the PI controllers are tuned by Ziegler Nichols tuning method. However it is observed that the controller performance deteriorates under varied drive operating conditions. It has been found from literature studies that the use of the stochastic optimization techniques for obtaining the optimized values of PI controllers are finding increased importance [1-9].

All stochastic optimization algorithms invariably require common controlling parameters like generations, population size etc. For different algorithms need their own algorithm specific control parameters like in particle swarm optimization the weight factor and acceleration constants. Similarly Harmonic Search Algorithm uses the pitch adjusting rate, harmony memory consideration rate and the number of improvisations etc.

The proposed study focuses on the Jaya optimization algorithm for tuning the gain values of speed PI controller. The main features of this algorithm are that it doesn't require any parameters to be initialized as required for other popular stochastic optimization technique as mentioned above. Moreover its implementation is simple with the probable solution updated only in a single phase using a single equation.

This paper has been organized in five sections. A generalized comparison between conventional DTC and modified DTC is presented in the following section i.e. Section-II. Section III briefs the optimization techniques mainly the Harmony Search and Jaya Algorithm and also the procedures to tune the PI controller. In section IV simulation results are described and finally conclusion is presented in section V. 


\section{DIRECT TORQUE CONTROL}

In a conventional DTC drive the IM is fed by VSI with the pulses for the switches obtained from the torque and flux hysteresis controllers. For the flux and torque hysteresis controllers the error of actual and reference values of torque and flux are used. The actual stator flux values in stationary d-q frame as shown in (3) are obtained from (1) and (2).

$$
\begin{aligned}
& \psi_{d s}=\int\left(V_{d s}-i_{d s} R_{s}\right) d t \\
& \psi_{q s}=\int\left(V_{q s}-i_{q s} R_{s}\right) d t
\end{aligned}
$$

Where, $v_{q s}, v_{d s}$ and currents $i_{d s}, i_{q s}$ are the transformed voltages and currents obtained from measured stator voltages $v_{a b c}$ and currents $i_{a b c}$ (3)

$$
\psi_{s}=\sqrt{\left(\psi_{q s}^{2}+\psi_{d s}^{2}\right)}
$$

Similarly the actual value of electromagnetic torque is given by (4).

$$
T_{e}=(3 / 2)(P / 2)\left(i_{q s} \psi_{d s}-i_{d s} \psi_{q s}\right)
$$

The limitation of conventional DTC is that the errors in torque and flux are within the specified band limits and thus limiting the range of switching selection for inverter. The proposed study makes use of the modified DTC controller where the hysteresis controllers for torque and flux are substituted by PI controllers as shown in Figure 1. The modification results in reducing the ripples in the developed torque of a conventional DTC IM drive without increasing the complexity using increased number of sectors required for space vector modulated inverter as reported in literature [10-13].

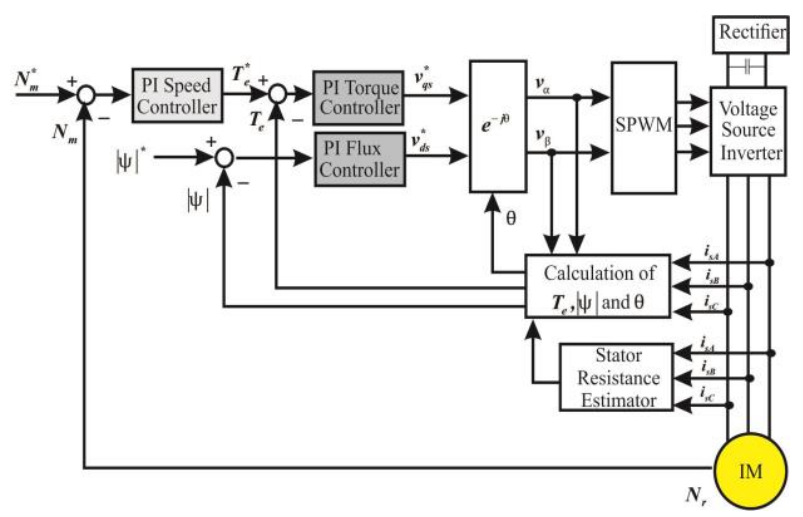

Figure 1. Block diagram of modified DTC using PI controllers

\section{PI CONTROLLER TUNING USING STOCHASTIC ALGORITHM}

\subsection{Pi controller}

In the modified DTC the error between the actual and reference speed of motor is processed by the speed PI controller to produce a torque command $T_{e}^{*}[14]-[15]$ as shown in Figure 2. Conventionally the gain values of PI controllers are obtained by following the tuning procedures of Ziegler Nichols method. It has been found from literature studies that proper tuned gain values of the speed PI controller is vital for enhancing the dynamic and steady state performance of a DTC drives. The proposed work focuses on the features of the stochastic optimization techniques in obtaining tuned gain values as discussed below.

\subsection{Harmony search}

HS proposed by Zong Woo Geem [16] is mostly not exaggerated by the size and nonlinearity of the problem. The concept of HSA is simple, easy to implement with less number of parameters. HS algorithm is inspired by the improvisation process of musicians and it is a phenomenon-mimicking algorithm. The correlation in between improvisation and optimization are as follows [17-19]: 
- $\quad$ Each musician corresponds to each decision variable.

- The decision variable's value range corresponds to musical instrument's pitch range.

- Musical harmony at a certain time corresponds to the solution vector at certain iteration.

- Objective function to be minimized or maximized corresponds to Audience's aesthetics.

The main steps of Harmony Search Algorithm are as follows:

- Initialize population size, number of design variables and termination criteria

- Identify best and worst solution.

- Improve harmony based on above solution.

- Check for termination condition.

- $\quad$ Report the optimum solution

The parameters of HS algorithm are given in Table 1.

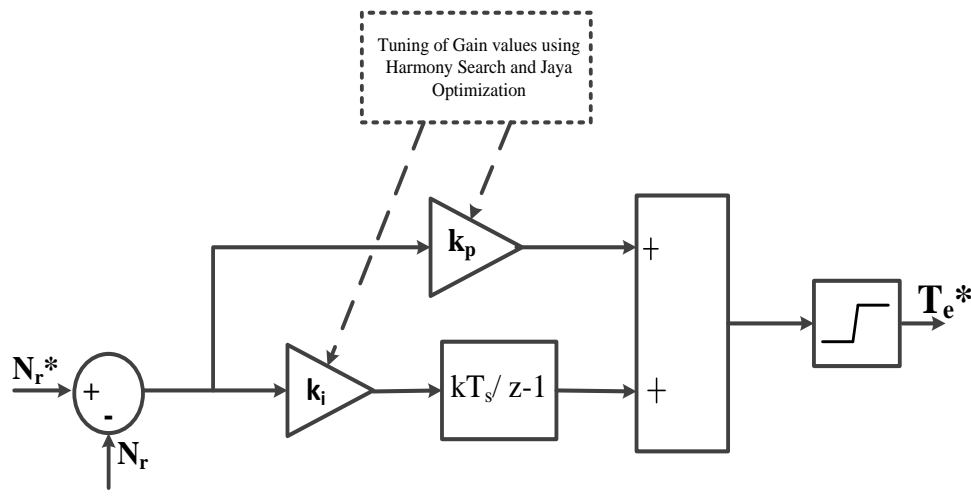

Figure 2. Block diagram of speed PI controller

Table 1. Optimization parameters

\begin{tabular}{cccc}
\hline \multicolumn{2}{c}{ Harmony Search } & \multicolumn{2}{c}{ Jaya Algorithm } \\
\hline Controlling Parameters & Values & Controlling Parameters & Values \\
Population size & 10 & Population size & 10 \\
Max. No. of Iteration & 20 & Max. No. of Iteration & 20 \\
Harmony Memory & 0.95 & & \\
Considering Rate & & & \\
Pitch Adjustment Rate & 0.3 & & \\
Band width (bw) & 0.2 & & \\
\hline
\end{tabular}

\subsection{Jaya algorithm}

This algorithm is based on the concept that the solution obtained for a given problem should move towards the best solution and should avoid the worst solution [20]. The algorithm is as follows. Let there be a objective function $f(x)$ with "m" number of design variables which is to be minimized or maximized. The " $m$ " number of candidates can be assumed to have " $n$ " number of candidate solution (i.e. population size, $f=1,2,3 \ldots, n$. Let the best candidate best obtains the best value of $f(x)$ in the entire candidate solutions and the worst candidate worst obtains the worst value of $f(x)$ in the entire candidate solutions. If $X_{i, j, k}$ is the value of the $i_{t h}$ variable for the $j_{t h}$ candidate for the $k_{t h}$ iteration, then this value of $X_{i, j, k}$ is modified as $X_{i+1, j, k}$ given in (5).

$$
X_{i+1, j, k}=X_{i, j, k}+r_{i, j, 1}\left(X_{i, j, b e s t}-\left|X_{i, j, k}\right|\right)-r_{i, j, 2}\left(X_{i, j, w o r s t}-\left|X_{i, j, k}\right|\right)
$$

In the above equation, $X_{i, j, b e s t}=$ best candidate value for variable $i$ and $X_{i, j, w o r s t}=$ worst candidate value for variable. $r_{i, j, 1}$ and $r_{i, j, 2}$ are the two random numbers for the $i_{t h}$ variable during the $k_{t h}$ iteration in the range [0,1]. The random numbers $r_{i, j, 1}$ and $r_{i, j, 2}$ acts as scaling factors. The second term of (5) indicates the tendency of the solution to move closer to the best solution and the third term indicates the tendency of the solution to avoid the worst solution. $X_{i+1, j, k}$ is accepted if it gives better objective function value. Figure 3 shows the flow chart of Jaya Algorithm. For both the stochastic algorithm the termination condition is fulfilled by the number of iteration which is kept same in both. 


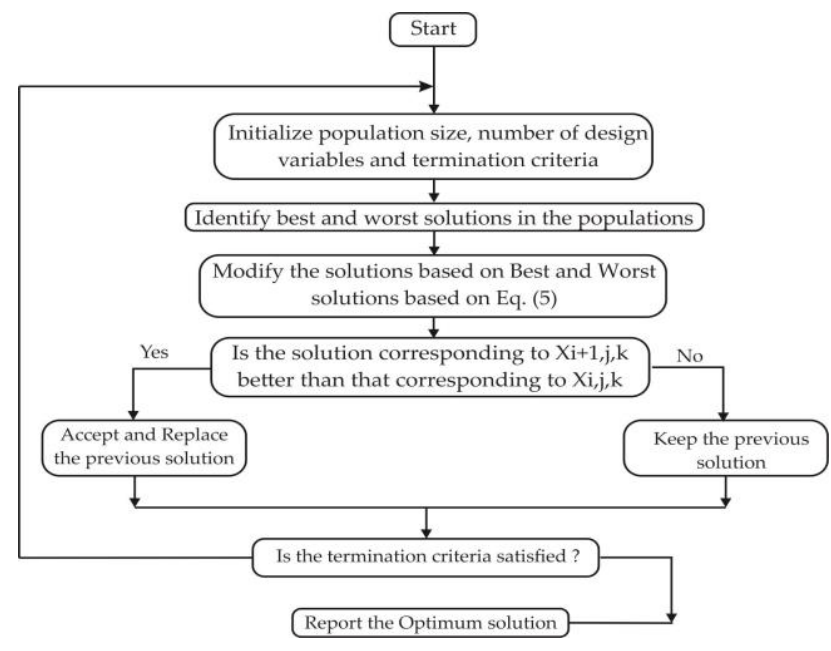

Figure 3. Flow chart of JAYA optimization

In this work, an Integral Time Absolute Error (ITAE) objective function is chosen for both the optimization technique. The objective function is given as in (6).

$$
f(x)=\int_{o}^{T} t|\Delta N|
$$

Where $\Delta N=N_{r}^{*}-N_{r}$ and $T$ is the total simulation time. For steady $T$ is taken as 10 sec. The optimized values of speed PI controller, corresponding objective function values and total run time of simulation are given in Table 2.

Table 2. $k_{p}, k_{i}$ and objective function values of optimization techniques

\begin{tabular}{ccc}
\hline Parameters & HS & JA \\
\hline$k_{p}$ & 2.0885 & 0.64194 \\
$k_{i}$ & 27.3784 & 29.0891 \\
Objective Function & $4.0565 \mathrm{e}+005$ & $4.03858 \mathrm{e}+05$ \\
Total Run Time (s) & 17214.920 & 2039.624 \\
\hline
\end{tabular}

\section{RESULTS AND DISCUSSION}

The modified DTC drive with the optimized gain values $k_{p}$ and $k_{i}$ of the speed controller is simulated in MATLAB/Simulink. The comparative analysis of the performance of the modified DTC drive for the HS and JAYA algorithm under different drive conditions are demonstrated with graph and tables. The performance analysis is made with reference to rise time, settling time and over shoot of the actual speed with respect to its reference values.

\subsection{Case-I: Constant speed and constant load torque}

The simulation study is first carried out at constant speed of $1000 \mathrm{rpm}$ with constant load torque showing the condition of a lathe drive as shown in Figure 4. From the zoomed speed response results it is observed that although there is an overshoot in the actual speed during starting transient for the speed controller with Jaya tuned gain values. However its rise time and settling time are lesser than the HS tuned speed controller. The performance comparison of the two speed PI controllers are summarised in Table 3. Figure 5 shows the comparison of the rise time, settling time and peak overshoot of the speed of the drive using graph for the proposed optimization techniques.

Table 3. Comparison of performance of drive at constant speed

\begin{tabular}{ccc}
\hline Parameters & HS & JA \\
\hline Rise Time (s) & 0.0732 & 0.0734 \\
Settling Time (s) & 0.1245 & 0.1239 \\
\% Over shoot (in \%) & 0.8245 & 0.7191 \\
Peak (rpm) & 1008.2 & 1007.2 \\
\hline
\end{tabular}




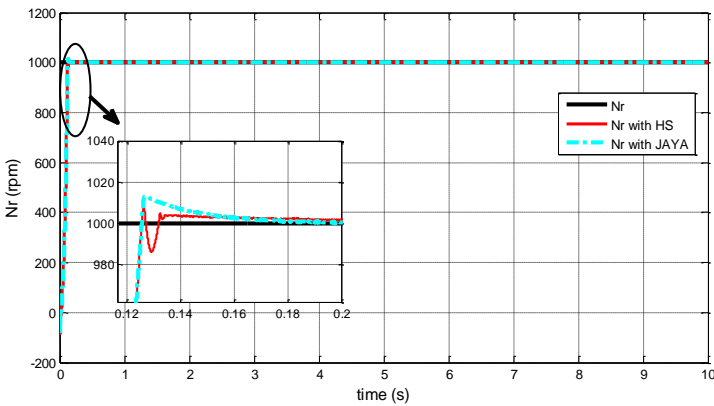

Figure 4. Speed $\left(N_{r}\right)$ response at constant speed $\left(N_{r}^{*}\right)$ and constant load torque $\left(T_{L}\right)$

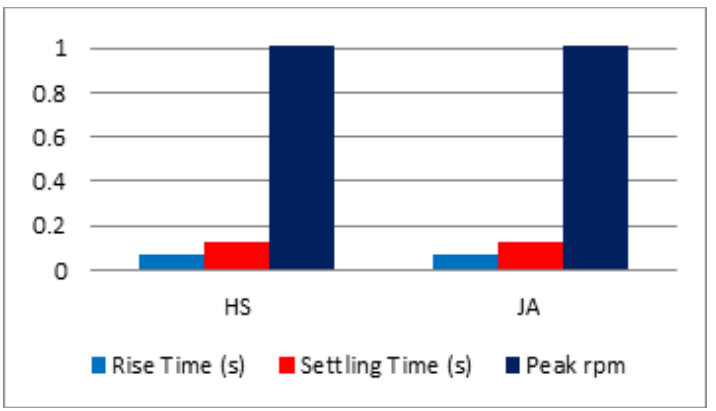

Figure 5. Graph showing the rise time, settling time and normalized rotor speed $\left(N_{r} / N_{r}^{*}\right)$ of drive in case I

Studies on the response of developed torque were also carried out as shown in Figure 6. It is seen that during transient the torque ripples of the JAYA tuned DTC drive is less than the HS based DTC drive. Moreover it is observed that there are no torque ripples during steady state conditions with low settling time. The same observation is made for the stator flux as shown in Figure 7.

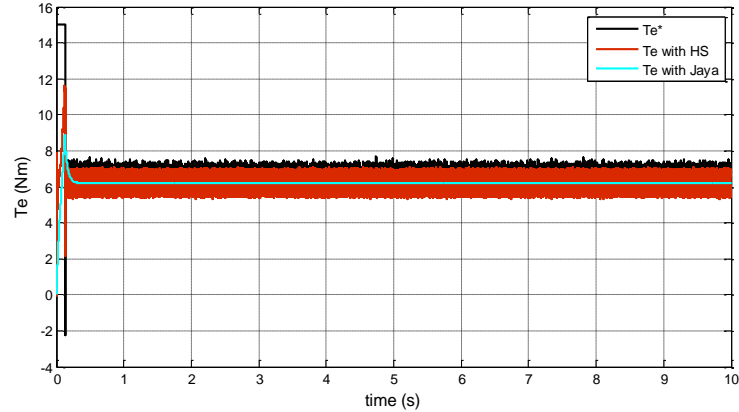

Figure 6. Response of developed torque $\left(T_{e}\right)$ at constant speed $\left(N_{r}^{*}\right)$ and constant load torque $\left(T_{L}\right)$

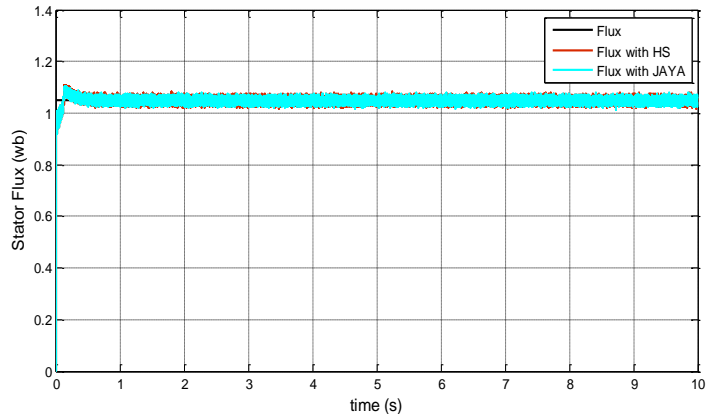

Figure 7. Stator flux response at constant speed $\left(N_{r}^{*}\right)$ and constant load torque $\left(T_{L}\right)$

\subsection{Case-II: Speed variation at constant load torque}

The DTC drive is now subjected to a condition with speed profile as shown in Figure 8 and at rated load torque of $5 \mathrm{Nm}$. The speed profile depicts the operating condition of a typical overhead crane. It is observed in Figure 8 that the DTC drive tracks the reference speed profile smoothly. However, it is seen that the settling time of the JA- PI speed controller is low as compared to the HS-PI speed controller. The enhanced performance of JA tuned controller with regard to peak overshoot and \% overshoot is also observed during drive starting condition. The performance comparison of the two speed PI controllers is given in Table 4 and through graph as shown in Figure 9.

Table 4. Comparison of performance of drive at variable speed

\begin{tabular}{ccc}
\hline Parameters & HS & JA \\
\hline Rise Time (s) & 0.0434 & 0.0434 \\
Settling Time (s) & 0.1053 & 0.1030 \\
$\%$ Over shoot (in \%) & 2.4664 & 2.2187 \\
Peak (rpm) & 409.88 & 408.95 \\
\hline
\end{tabular}

One of the major drawbacks of DTC drive is the torque ripples. Figure 10 shows the simulation results of the electromagnetic torque $T_{e}$ developed. On comparison with the HS tuned speed controller it is observed that settling time, peak and torque ripple of $T_{e}$ for the JA tuned speed controller is very less. Apart from that it is seen during speed changes, the performance characteristics of stator flux response as shown in Figure 11 for the JA- PI controller is optimum. 


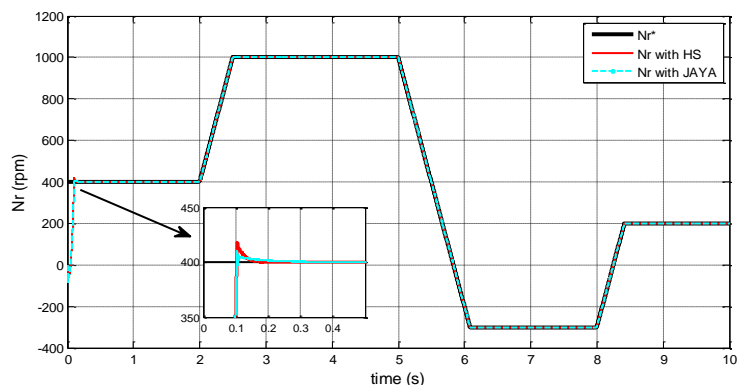

Figure 8. Speed $\left(N_{r}\right)$ response at variable speed $\left(N_{r}^{*}\right)$ and constant load torque $\left(T_{L}\right)$

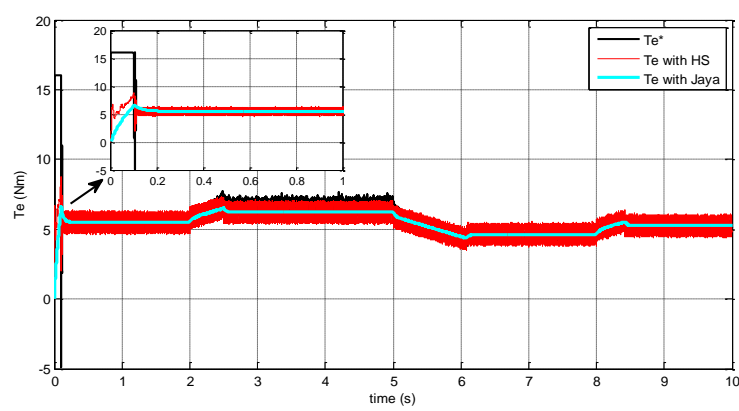

Figure 10. Response of developed torque $\left(T_{e}\right)$ at variable speed $\left(N_{r}^{*}\right)$ and constant load torque $\left(T_{L}\right)$

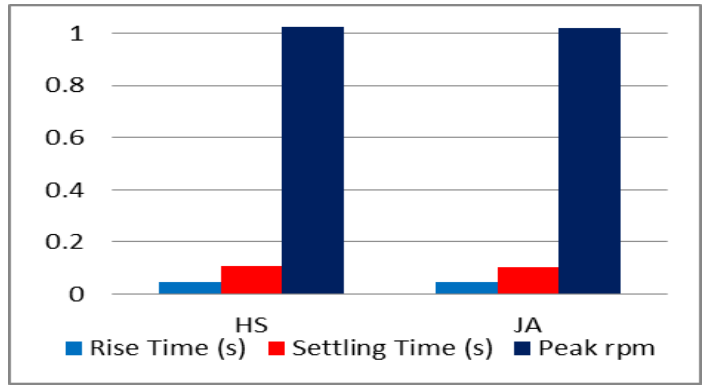

Figure 9. Graph showing the rise time, settling time and normalized rotor speed $\left(N_{r} / N_{r}^{*}\right)$ of drive in case II

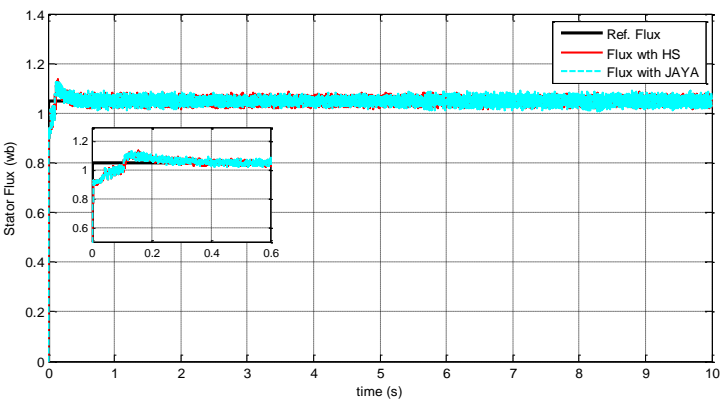

Figure 11. Stator flux response at variable speed $\left(N_{r}^{*}\right)$ and constant load torque $\left(T_{L}\right)$

\subsection{Case-III: Constant speed and variable load torque}

In this case the DTC drive operates at constant speed of $900 \mathrm{rpm}$ but with variable load torque. The variable torque operating condition occurs for a roller motor drive in steel industries or a conveyor drive in material handling plant. Initially drive runs at no load till $4 \mathrm{~s}$, after that the load torque increases to $2 \mathrm{Nm}$ till $7 \mathrm{~s}$. At $7 \mathrm{~s}$ torque is again increased to $4 \mathrm{Nm}$ till the end of the simulation.

The simulation result of speed response is shown in Figure 12. During step changes in load torque there is a small variation in speed. It is observed that with JA optimization the effect of load torque variation is less as compared to HS technique. During the start, at no load the settling time of motor is $11.06 \%$ less as compared to HS, which is a tremendous difference. Not only the settling time but peak over shoot is also 22.7 $\%$ less with JA. The rise time, settling time and peak over shoot (with respect to the reference speed) graphs shown in Figure 13. The performance analysis of the DTC drive for the two optimized speed controller is shown in Table 5 with the corresponding graphs. The simulation results for the $T_{e}$ developed and the stator flux as shown in Figure 14 and 15 shows better performance of the JA tuned PI controller especially during transient condition.

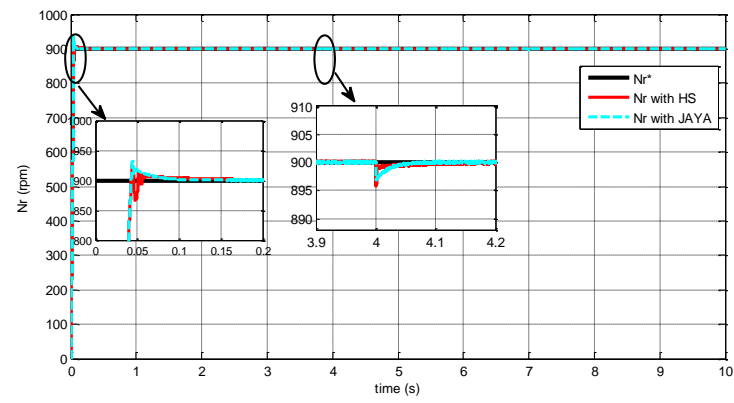

Figure 12. Speed $\left(N_{r}\right)$ response at constant speed $\left(N_{r}^{*}\right)$ and variable load torque $\left(T_{L}\right)$

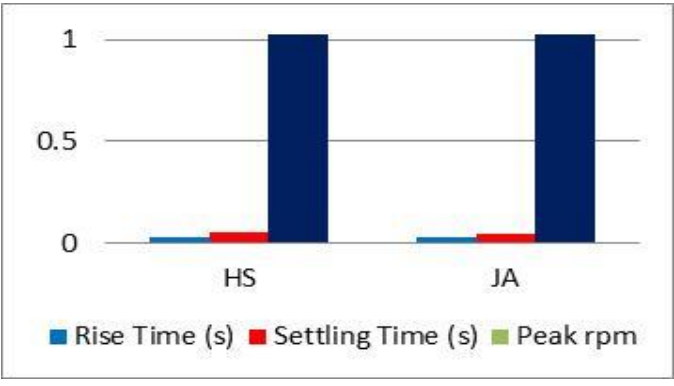

Figure 13. Graph showing the rise time, settling time and normalized rotor speed $\left(N_{r} / N_{r}^{*}\right)$ of drive in case III 


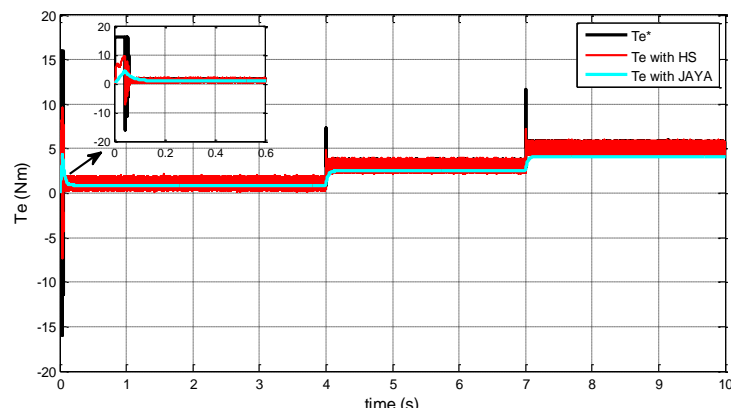

Figure 14. Response of developed torque $\left(T_{e}\right)$ at constant speed $\left(N_{r}^{*}\right)$ and variable load torque $\left(T_{L}\right)$

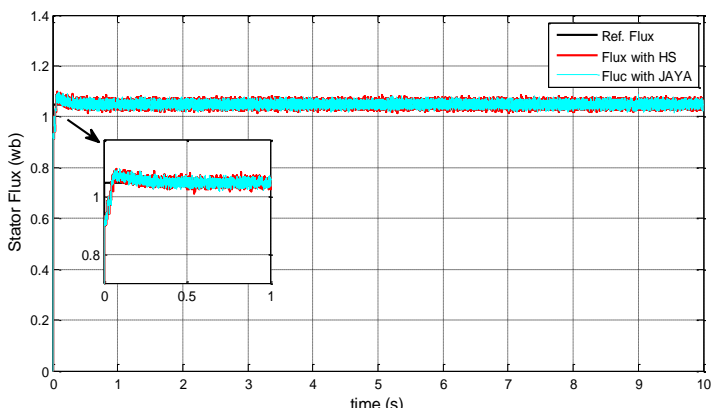

Figure 15. Stator flux response at constant speed $\left(N_{r}^{*}\right)$ and variable load torque $\left(T_{L}\right)$

Table 5. Comparison of performance of drive at constant speed and variable load torque

\begin{tabular}{ccc}
\hline Parameters & HS & JA \\
\hline Rise Time (s) & 0.0300 & 0.0300 \\
Settling Time (s) & 0.0505 & 0.0449 \\
$\%$ Over shoot (in \%) & 2.8640 & 2.6370 \\
Peak (rpm) & 925.86 & 923.72 \\
\hline
\end{tabular}

\section{CONCLUSION}

This paper has presented a parameter less optimization algorithm for tuning the gains of the speed controller of modified DTC drive. The investigations carried out clearly shows that where frequent changes in operating condition occur, the performance of the proposed JAYA tuned speed PI controller is better than the Harmony search tune PI controller. It is seen from the results that the peak overshoot, rise time, or the settling time in the tracking of speed response during load disturbance or change in drive speed profile is minimal. Also the reduction in ripple in the developed torque or stator flux is considerably less than that of the Harmony Search tuned modified DTC drive.

\section{REFERENCES}

[1] K.J. Astrom and T. Hagglund, "PI Controllers: Theory, Design, and Tuning Instrument," Society of America.

[2] Rasmus K. Ursem and Pierre Vadstrup, "Parameter identification of induction motors using stochastic optimization algorithms," Applied Soft Computing, vol. 4, no.1, pp. 49-64, 2004.

[3] N. Rajasekar and K.Mohana Sundram, "Feedback controller design for variable voltage variable speed induction motor drive via Ant Colony Optimization," Applied Soft Computing, vol. 12, no. 8, pp. 2132-2136, 2012.

[4] Mushtaq Najeeb, et al., "An Efficient Control Implementation for Inverter Based Harmony Search Algorithm," International Journal of Power Electronics and Drive Systems, vol. 8, no.1, pp. 279-289, 2017.

[5] O. Roeva and T. Slavov, "Firefly Algorithm Tuning of PID Controller for Glucose Concentration Control during E. coli Fed-batch Cultivation Process" Proceedings of the Federated Conference on Computer Science and Information Systems, pp. 455-462, 2012.

[6] E.S. Ali, "Speed control of DC series motor supplied by photovoltaic system via firefly algorithm," Neural Computing \& Applications, vol. 26, no. 6, pp. 1321-1332.

[7] Mohanasundaram Kuppusamy and Rajasekar Natarajan, "Genetic Algorithm Based Proportional Integral Controller Design for Induction Motor,” Journal of Computer Science, vol. 7, no. 3, pp. 416-420, 2011.

[8] M.M. Eissa, et al., "Optimum Induction Motor Speed Control Technique Using Genetic Algorithm," American Journal of Intelligent Systems, vol. 3, no. 1, pp. 1-12, 2013.

[9] P. Brandstetter and M. Dobrovsky, "Speed Control of A.C. Drive with Induction Motor Using Genetic Algorithm," International Joint Conference CISIS'12-ICEUTE'12-SOCO'12 Special Sessions. Advances in Intelligent Systems and Computing, vol.189, Springer, Berlin, Heidelberg, 2013.

[10] R. Essakiraj, et al., "Speed Control of Induction Machines Using GA Based PID Controller," Middle-East Journal of Scientific Research, vol. 23, (Sensing, Signal Processing and Security), pp. 164-169, 2015.

[11] J.C. Basilio and S.R. Matos, "Design of PI and PID Controllers with Transient Performance Specification," IEEE Transactions on Education, vol. 45, no. 4, pp. 364-370, 2002.

[12] S. Rao and T.V. Kumar, "Direct Torque Control of Induction Motor Drives for Optimum Stator Flux and Torque Ripple,” IEEE PEDS . Singapore, pp. 952-955. 2011.

[13] L. Tang and M.F. Rahman, "A New Direct Torque Control Strategy for Flux and Torque Ripple Reduction for Induction Motors Drive-a Matlab/Simulink Model," (IEMDC 2001). IEEE International Electric Machines and Drives Conference, Cambridge, MA, pp. 884-890, 2001. 
[14] C. Lascu, et al., "A modified direct torque control (DTC) for induction motor sensorless drive," IEEE Trans. on Industry Application, vol. 36, no. 1, pp. 122-130, 2000.

[15] Rahul Malhotra, et al., "Genetic Algorithms: Concepts, Design for Optimization of Process Controllers," Computer and Information Science, vol. 4, no. 2, pp. 39-54, 2011.

[16] Z. W. Geem, et al., "A new heuristic optimization algorithm," Harmony search Simulation, vol. 76, no. 2, pp. 60-68, 2001.

[17] Yang Xin She, "Harmony Search as a Metaheuristic Algorithm," In: Geem Z.W. (eds) Music-Inspired Harmony Search Algorithm, Studies in Computational Intelligence. Springer, Berlin, Heidelberg, vol. 191, pp.1-14, 2009.

[18] Salem Mohammed, et al., "Statistical Analysis of Harmony Search Algorithms in Tuning PID Controller," International Journal of Intelligent Engineering \& Systems, vol. 9, no. 4, pp. 98-106, 2016.

[19] A. Hameed kalifullah and S. Palani, "Optimal tuning of PID power system stabilizer for multi machine power system using Harmony Search Algorithm," Journal of Theoretical and Applied Information Technology, vol. 66, no.2, pp. 513-520, 2014.

[20] R, Venkata Rao, "Jaya: A simple and new optimization algorithm for solving constrained and unconstrained optimization problems," International Journal of Industrial Engineering Computations, vol. 7, pp. 19-34, 2016.

\section{BIOGRAPHIES OF AUTHORS}
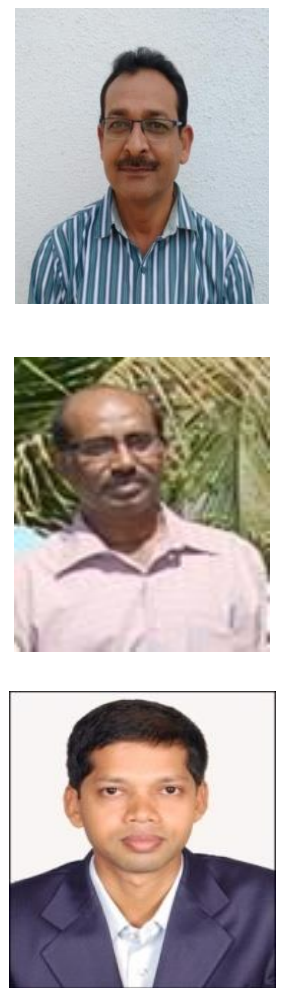

Naveen Goel was born in Haridwar (U.P.), India in 1968. He received his BE degree in Electrical Engineering from Jiwaji University, Gwalior (M.P.) in 1992 and ME in Electrical Engineering (PE) from Shri Govind Ram Sakseria Institute Technology and Science, Indore, (M.P), in 2006. He is currently served as HOD of Electrical and Electronics Engineering at Shri Shankaracharya Technical Campus, Bhilai, (C.G), India and is currently pursuing his Ph.D. from Swami Vivekanand Technical University, Bhilai (C.G.), India. He is the author of 5 International Journal and Conference and 5 National conferences. His area of research is Power Electronics and drives, Custom power devices, application of soft computing techniques for estimation and fault detection in Electric Drives.

Dr. Saji T Chacko was born in Chattisgarh, (C.G), India in 1968. He was a faculty of Electrical and Electronics Engineering at Shri Shankaracharya Technical Campus, Bhilai and currently Head of Department, Electrical Government Polytechnic College C.G, India. He got his PhD from Maulana Azad National Institute of Technology, Bhopal, M.P,India. He is the author of 10 Journal and 15 conference papers in National and International Publications. His area of research interest is Power Electronics and Drives, Power quality issues and application of Soft Computing techniques for estimation and fault detection.

Dr. R. N. Patel did his Ph. D. in the area of Power Systems from the Indian Institute of Technology (IIT) New Delhi, INDIA in the year 2003. Prior to this he obtained his M. Tech. from IIT Delhi and graduate degree in Electrical Engineering from SGSITS Indore. Dr. Patel served as a Faculty in the Electrical Engineering department at IIT Roorkee from the year 2003 to 2006 . He has also served in Faculty position at the Birla Institute of Technology and Science, Pilani. Presently he is working as Professor in the department of Electrical and Electronics Engineering at Shri Shankaracharya Technical Campus, Bhilai, INDIA. Dr. Patel has many publications in various international journals of repute, presented his research at various international conferences and has also organized many national Workshops and Conferences. He is a recipient of prestigious 'Career Award for Young Teachers', from AICTE-New Delhi, INDIA. Dr. Patel has successfully handled many research projects, sponsored (/funded) by AICTE, New Delhi and Department of Science and Technology (DST), Govt. of INDIA, New Delhi. 